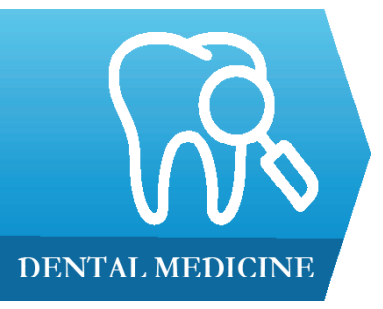

1) Department of General Clinical Dentistry, Rajiv Gandhi University of Health Sciences, Karimganj, India

2) Oral Maxillofacial Surgeon, Dental Health Care \& Research Unit, Gharonda, Bangalore, Karnataka, India

3) Dental Health Care \& Research Unit, Gharonda, Bangalore, Karnataka, India

DOI: $10.15386 / \mathrm{mpr}-1459$

Manuscript received: 05.08.2019

Received in revised form: 05.10.2019

Accepted: 19.01.2020

Address for correspondence:

drnyeromfs@gmail.com

This work is licensed under a Creative Commons Attribution-NonCommercialNoDerivatives 4.0 International License

\title{
An unusual clinical vignette of oro-pharyngeal discomfort: Pterygoid Hamulus syndrome
}

\author{
Ayasha Firdouse $^{1}$, Nyer Firdoose ${ }^{2}, \mathrm{~S}_{\text {Ghousia }}{ }^{3}$
}

\begin{abstract}
Background. A straightforward clinical reasoning is always difficult in patients with persistent orofacial pain with vague symptoms. Craniofacial pain or Orofacial pain can have a mixture of causes ranging from neurogenic, myogenic, and psychogenic factors intertwined amidst the intricate anatomy with a high vascular network. This plethora of uncertainty blurs the judgment for such patients to whom we provide care. We hereby present a case of a 17 year old female with vague pain on talking, chewing and even swallowing when initially examined; this chronic orofacial pain often worsened her quality of life. The aim of this manuscript is to present a case of Pterygoid Hamulus syndrome that was misdiagnosed as glossopharyngeal and myofascial neuralgia.
\end{abstract}

Methods. The condition was managed by surgical excision of the elongated pterygoid hamulus, following a recurrence of her symptoms.

Results. The patient was relieved of pain only after the surgical excision of the elongated hamulus.

Conclusions. The surgery was decided upon only after conservative management had not provided much relief and the manuscript also discusses the ambiguous composite pain referral pattern in Pterygoid Hamulus syndrome.

Keywords: bursitis, pharynx, Pterygoid Hamulus, orofacial neuralgia, soft palate

\section{Introduction}

Chronic orofacial pain comprises of an extensive spectrum of pain disorders due to its unique physiologic, anatomic and biochemical components. Individuals with persistent orofacial pain never present with definitive symptoms that allow for a straightforward clinical diagnosis. It can have a tone of myogenic, psychogenic and neurogenic causes. This aegis of uncertainty blurs the judgment for every patient whom we treat. The quality of life with chronic orofacial pain often seems to worsen with concurrent use of multiple medications by different doctors and have their own consequences finally leading to over diagnosis and overtreatment.

Pain in the soft palate or pharyngeal region may occur due to various causes. Such pain is very difficult to diagnose because its varied origins may include vascular, muscular, ligamental, and/or osseous factors [1]. Although the pterygoid hamulus (PH) of the sphenoid bone may be responsible for atypical pain in this region, the etiology of this syndrome is not fully understood. Any of the following factors may be responsible: bursitis or an osteophyte in the tensor veli palatini, elongation of the $\mathrm{PH}$, consistent repetition of minimal trauma to the overlying soft tissue and $\mathrm{PH}$, hyperawareness of the $\mathrm{PH}$, muscular discoordination, or fracture of the $\mathrm{PH}$ after extensive and repeated manipulation [2]. Patients usually present with pain or an abnormal sensation, such as irritation or burning, in the oral cavity.

\section{Case description and results}

A 17 year old Indian female reported to our dental operatory with difficulty in mouth opening, vague 
pain on swallowing in and around the throat, ears and difficulty in chewing, talking which debilitated her in her daily life for over 12 months. The pain could not be localized to one particular region and was oppressive and spontaneous in nature. She gave a history of a burning sensation, a pricking type of dysesthesia in her lip region and intermittent and radiating pain to the bilateral temporal, orbital and temporomandibular joint region. The nature of pain made her aggressive, agitated and anxious with lack of sleep. No trigger factors, aggravating and or relieving factors were disclosed by the patient. Her medical history was unremarkable except for ingestion of a combination of drugs alternating from antibiotics, analgesics, steroids, and antidepressants prescribed by multiple physicians for the chronic unrelenting pain. She was previously diagnosed for glossopharyngeal neuralgia and myofascial pain dysfunction syndrome. Appropriate management for these conditions failed to improve her symptoms. The patient was even referred to psychiatric counseling for her incessant pain.

\section{Clinical Examination}

Intra oral palpation revealed bilateral tenderness overlying the pterygoid hamulus region. Initial treatment with an injection of $1 \mathrm{ml}$ of dexamethasone in the area of tenderness resulted in a drastic improvement.

\section{Investigations}

\section{Orthopantomogram}

The panoramic radiograph revealed possible elongation of the pterygoid hamulus bilaterally (Figure 1).

Cone beam computed tomogram (CBCT)

An anatomic review using a CBCT scan disclosed the presence of elongation (Figure 2) with acute bending of the pterygoid hamulus to protect the tensor veli palatine tendon. A diagnosis of Pterygoid Hamulus Syndrome was made due to the drastic improvement in the patient's symptoms as a result of corticosteroid therapy.

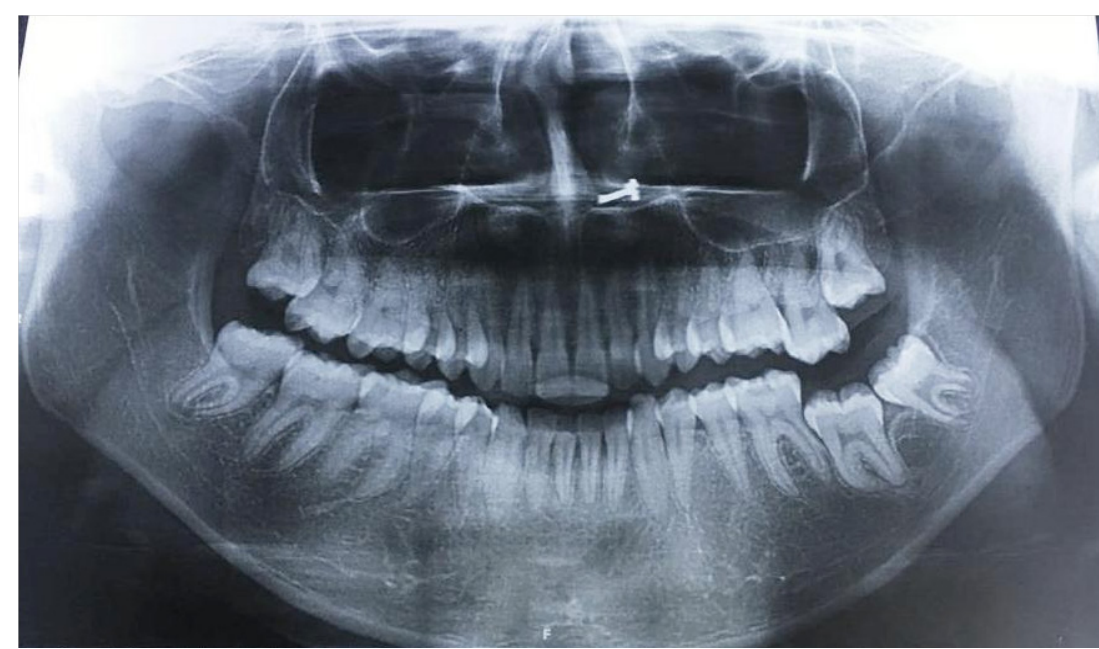

Figure 1. Panoramic radiograph revealing possible elongation of pterygoid hamulus.

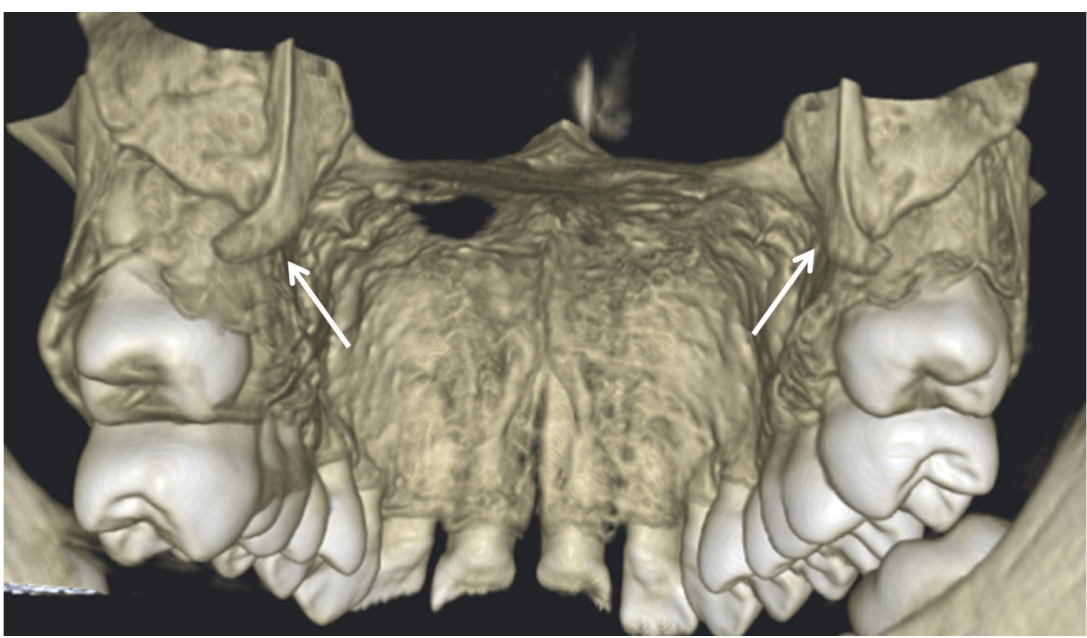

Figure 2. CBCT scan disclosing the presence of elongation of the pterygoid hamulus with acute bending of the pterygoid hamulus to protect the tensor veli palatine tendon. 
The treatment plan comprising the conservative management by corticosteroid therapy, provided her with intermittent relief. The surgical excision (Figure 3-4) of the elongated pterygoid hamulus was performed after the therapy which resulted in the patient being pain free till date.

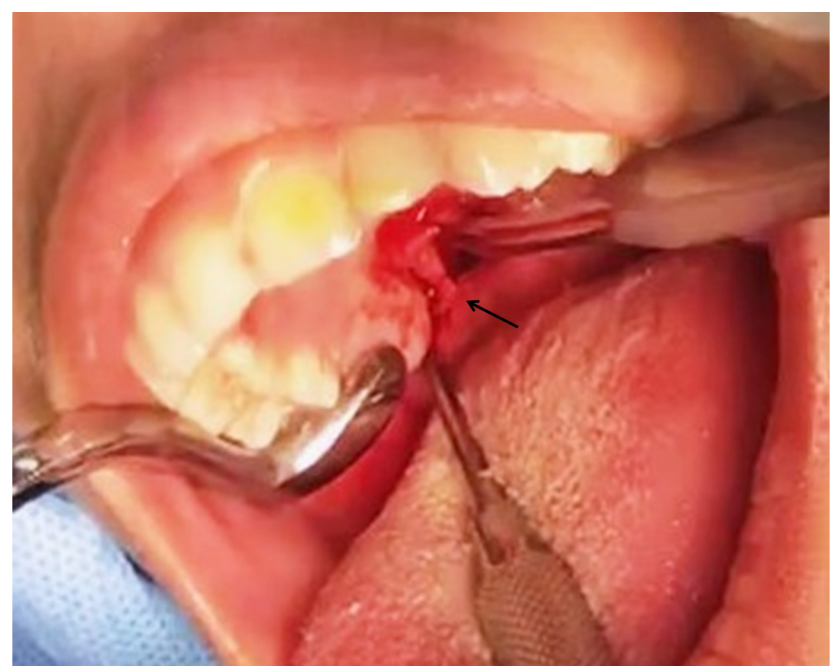

Figure 3. Surgical excision of the elongated pterygoid hamulus.

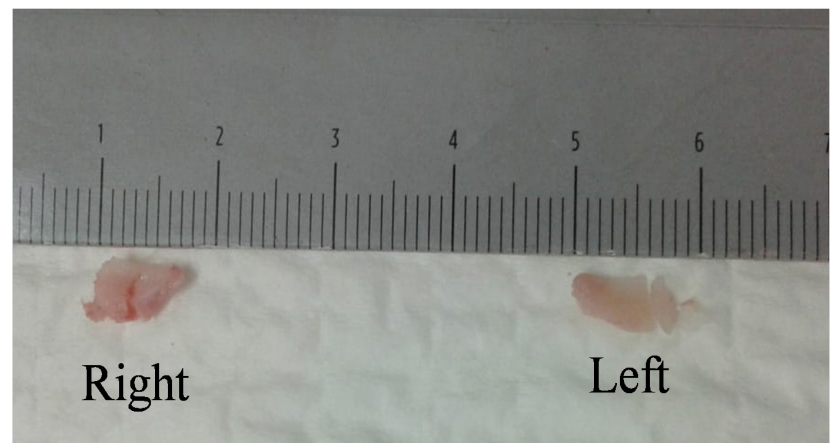

Figure 4. Excised pieces of elongated Pterygoid Hamulus.

\section{Discussion}

Anatomically the pterygoid hamulus is a capricious structure having a: base, corpus, sulcus, and caput. The average measurements are length $7.2 \mathrm{~mm}$, sagittal breadth $1.4 \mathrm{~mm}$, and transverse breadth of $2.3 \mathrm{~mm}$, the average inclination of the $\mathrm{PH}$ is $75^{\circ}$ in the sagittal plane and $58^{\circ}$ in the frontal plane $[4,5]$. The muscle attachment within the hamulus subjects its body to a greater load in the mesio dorsal direction, while the head of the hamulus can be freely pulled away laterally and caudally [5].

Within the ever growing evidence pertaining to the morphology and position of pterygoid hamulus amongst different populations, the average length was stated to be within the range of 4.9 to $7.2 \mathrm{~mm} \mathrm{[5-10].} \mathrm{This} \mathrm{is} \mathrm{in}$ contrast to the length of $16.5 \mathrm{~mm}$ on right side and $15.6 \mathrm{~mm}$ over the left side as seen in our case (Figure 5). This was suggestive of mechanical stimulation to the neighboring tissues by the elongated pterygoid hamulus eliciting pain thereby impairing the smooth functioning of the tensor veli palatini muscle. Confirming the elongated pterygoid hamulus radiographically, a reasonable explanation for the pain can be postulated: (1) thin and friable mucosa over the soft palate than usual; (2) proximity of soft palate to pterygoid hamulus making it vulnerable to any frictional trauma [11] and (3) Pterygoid plate asymmetry [12].

The term "pterygoid hamulus syndrome" was designated in 1987 by Hjorting-Hansen and Lous [2,3] which was characterized by pain in the palatal and pharyngeal regions, attributed to an elongated pterygoid hamulus. The seemingly normal clinical picture of the oral cavity can baffle the clinician. Pterygoid hamulus bursitis is one such rare entity showing a cluster of symptoms in the orofacial region. The contraction of the tensor veli palatini muscle creates tension in the soft palate and helps to open the Eustachian tube during speech, deglutition, mastication, respiration, yawning and sneezing. Therefore, PHS pain can be varied from earache, otic fullness, odynophagia, dysphagia, gustative hyperesthesia, pain in soft palate, jaw pain, dysaesthesias and even headaches [1].

Some of its clinical presentations may imitate temporomandibular joint disorders and glossopharyngeal neuralgia $[13,14]$. Alertness of this fascinating entity is essential to every health practitioner concerned in the diagnosis and management of orofacial pain. It would be effectual to carefully listen to patients while they narrate their history as this can refine the maladies involving the orofacial structures and adopt a dual axis approach. The purpose of this script is to elaborate a case of pterygoid hamulus syndrome managed by surgical trimming of the pterygoid hamulus following a failure of conservative therapy and discuss its complex pain referral pattern. In patients with undiagnosed sporadic facial and/or neck pain, an elongated pterygoid hamulus or a styloid process needs to be included in the diagnostic cascade of orofacial pain.

\section{Conclusions}

PHS is a vicious cause of orofacial/oropharyngeal pain. It can be associated with a hamulus hypertrophy or with a bursa over the palatosalpingeus but does not always have an anatomic cause. Pain in the oropharyngeal region while swallowing while doing normal movements like opening and closing of the mouth is hard to diagnose. The patient may be the victim of misdiagnosis and mismanagement leading to a psychological overhaul which blurs the initial complaints therefore this dreadful circle of events needs to be interrupted by careful diagnosis. 


\section{References}

1. Cho JY, Cheon KY, Shin DW, Chun WB, Lee H. Pterygoid hamulus bursitis as a cause of craniofacial pain: a case report. J Korean Assoc Oral Maxillofac Surg. 2013;39:134-138.

2. Eyrich GK, Locher MC, Warnke T, Sailer HF. The pterygoid hamulus as a pain-inducing factor: A report of a case and a radiographic study. Int J Oral Maxillofac Surg. 1997;26:275277.

3. Sattur AP, Burde KN, Goyal M, Naikmasur VG. Unusual cause of palatal pain. Oral Radiology. 2011; 27(1):60-63.

4. Sasaki T, Imai Y, Fujibayashi T. A case of elongated pterygoid hamulus syndrome. Oral Dis. 2001;7:131-133.

5. Krmpotić-Nemanić J, Vinter I, Marusić A. Relations of the pterygoid hamulus and hard palate in children and adults: anatomical implications for the function of the soft palate. Ann Anat. 2006;188:69-74.

6. Abe M, Murakami G, Noguchi M, Kitamura S, Shimada $\mathrm{K}$, Kohama GI. Variations in the tensor veli palatini muscle with special reference to its origin and insertion. Cleft Palate Craniofac J. 2004;41:474-484.

7. Orhan K, Sakul BU, Oz U, Bilecenoglu B. Evaluation of the pterygoid hamulus morphology using cone beam computed tomography. Oral Surg Oral Med Oral Pathol Oral Radiol Endod. 2011;112:e48-e55.

8. Roode GJ, Bütow KW. Pterygoid hamulus syndrome undiagnosed. SADJ. 2014;69:70-71.

9. Barchetta NF, de Oliveira RLB, Silveira VAS,. Faig-Leite H. Clinical and morphofunctional aspects of pterygoid hamulus: literature review. Brazilian Dental Science, 2015;18:5-11.

10. Guerrero ME, Beltran J, de Laat A, Jacobs R. Can pterygoid plate asymmetry be linked to temporomandibular joint disorders? Imaging Sci Dent. 2015;45:89-94.

11. Charbeneau TD, Blanton PL. The pterygoid hamulus: A consideration in the diagnosis of posterior palatal lesions. Oral Surg Oral Med Oral Pathol. 1981;52:574-576.

12. Siqueira JT, Lin HC, Nasri C, Siqueira SR, Teixeira MJ, Heir $\mathrm{G}$, et al. Clinical study of patients with persistent orofacial pain. Arq Neuropsiquiatr. 2004;62:988-996.

13. Rollman GB, Lautenbacher S. Sex differences in musculoskeletal pain. Clin J Pain. 2001;17:20-24.

14. Barsky AJ, Peekna HM, Borus JF. Somatic symptom reporting in women and men. J Gen Intern Med. 2001;16:266-275. 